\title{
Responsabilidade Social e Ambiental das Empresas. Uma perspectiva sociológica.
}

Maria Paula Vilhena Mascarenhas* Cristiana dos A. Fernandes Costa*

\section{Resumo:}

Até que ponto a intervenção humana, na área da produção, está a ter em conta a problemática do ambiente? O objetivo do estudo consiste em saber se os atores sociais das empresas agem de forma consciente, escolhendo um caminho árduo em consonância com um desenvolvimento sustentável ou se optam por um crescimento sem a preocupação com as consequências das suas atividades no Ambiente. Revelando-se assim, essencial a análise entre a Responsabilidade Ambiental e o Marketing Social a partir dos Rótulos Ambientais. De fato, as empresas têm preocupações ambientais, tendo como base o uso racional dos recursos naturais. E é, sem dúvida, a reciclagem de resíduos, próprios ou gerados pelos consumidores, a grande tendência para diminuição do impacto ambiental das empresas. Porém, estas preocupações ambientais incidem essencialmente na sobrevivência empresarial, a questão ambiental nas empresas já não é apenas um altruísmo ligado à biosfera, mas também um requisito aos novos moldes de produção. Poder-se-á dizer que o impacto externo, meios pelos quais tomam conhecimento, acerca das questões ambientais, influenciam as escolhas das empresas.

Palavras-chave: responsabilidade social e ambiental, marketing social, rótulos ambientais.

\section{Abstract:}

How far human intervention in the area of production, is taking into account the problems of the environment? How far human intervention in the area of production, is taking into account the problems of the environment? The objective of the study is whether the social actors of the companies act consciously, choosing

\footnotetext{
* Doutorada, Professora auxiliar da Universidade do Minho, Departamento de Sociologia e investigadora do Centro de Investigação em Ciências Sociais - CICS, e-mail: pvmascarenhas@ics.uminho.pt

"Mestre em Sociologia das Organizações e Trabalho, e-mail: cristiana.afcosta@gmail.com
}

Latitude, vol. 7, n², pp.141-167, 2011

DOI: https://doi.org/10.28998/2179-5428.20110207 


\section{Responsabilidade Social e Ambiental das Empresas. Uma perspectiva sociológica.}

a difficult path in line with sustainable development or opts for growth without concern for the consequences of their activities on the environment. Revealing analysis is essential between Environmental Responsibility and Social Marketing from the Environmental Labels. In fact, companies have environmental concerns, based on the rational use of natural resources. It is certainly residues recycling own or generated by consumers, tend to decrease the environmental impact of companies. However, these environmental concerns focus essentially on business survival, environmental issues in business is not just altruism on the biosphere, but also a requirement for new production molds. It could be said that the external impact, the means by which they acquire knowledge, on environmental issues, influence the choices of companies.

Keywords: social and environmental responsibility, social marketing, environmental labels.

\footnotetext{
«Para se alcançar um Desenvolvimento Sustentável, a Proteção Ambiental deve constituir parte integrante do processo de desenvolvimento e não pode ser considerada separadamente» (Declaração do Rio sobre Ambiente - UNCED Junho 92).
}

\section{Introdução}

A responsabilidade social e ambiental nas empresas tem sido objeto de investigações por parte das Ciências Sociais, em particular na Economia e na Gestão. Recentemente, assiste-se a um despertar dos sociólogos por esta temática. Os anos noventa do século passado e a primeira década do século XXI foram marcados por uma ampla divulgação dos riscos ambientais pelos meios de comunicação social. A degradação da qualidade da água e do ar, a contaminação e a erosão dos solos, o esgotamento dos combustíveis fósseis, a destruição da camada de ozono, a desflorestação agressiva, as chuvas ácidas, a extinção de espécies e as alterações climáticas, entre outros problemas ambientais, contribuíram para a redução da qualidade de vida. Estas questões ambientais têm vindo a ser amplamente discutidas na Comissão Europeia. Para esta perceção dos riscos ambientais, muito contribuíram os movimentos ambientalistas que divulgaram e tornaram mais acessível a informação científica, defendendo uma mudança nas práticas, atitudes e valores na sociedade. A sua participação nas instituições públicas e privadas e no poder político desencadeou políticas que visam um desenvolvimento sustentável. O $6^{\circ}$ Programa de Ação Comunitária em matéria de Ambiente salienta que "muitos europeus já se consciencializaram de 
Maria Paula Vilhena Mascarenhas

Cristiana dos A. Fernandes Costa

que precisamos de agir para proteger o planeta e utilizar os nossos recursos naturais de forma mais prudente e eficiente. Têm que ser aproveitadas as oportunidades de inovação para melhorar o ambiente e a economia. No entanto, muito há ainda a fazer. Para continuar a progredir, tem que se colocar o ambiente no centro das decisões sobre qualquer matéria desde os transportes à energia, da indústria à agricultura" (Comissão Europeia, 2001-2010, p. 3-4).

De um modo geral, as organizações são responsáveis por uma quantidade considerável de posições na concorrência e a própria permanência ou saída do mercado da degradação ambiental. Qualquer tentativa de alterar comportamentos exige uma mudança fundamental dos valores e da atitude dos gestores (CNUAD, 1992).

Entre as diversas exigências contestadas pela sociedade moderna, que interferem com a atividade empresarial, a preocupação ambiental tem ganho projeção significativa face à sua relevância para a qualidade de vida das populações. Como consequência destas pressões no seio de muitas organizações, sobre os problemas ambientais, as questões ambientais passam a fazer parte de um quadro de ameaças e oportunidades cujas consequências podem significar posições na concorrência e/ou a própria permanência ou saída do mercado (Comissão Europeia, 2001; United Nations, 1998).

No discurso da «solidariedade social», a responsabilidade social das empresas tende a ser colocada na mesma base da cidadania individual dado que pressupõe que ambas tenham o mesmo exercício de direitos e cumprimento de deveres orientados por valores éticos e, não apenas, pela imposição de normas jurídicas. Assim sendo, nesta perspetiva, a implementação da responsabilidade social e ambiental nas empresas, poderia gerar efeitos positivos tanto para a sociedade como para as empresas, contribuindo para mudanças organizacionais, sociais e culturais.

Deste modo, "a responsabilidade social remete para a constituição de uma cidadania organizacional no âmbito interno da empresa e para a implementação de direitos sociais no âmbito externo" (Srour, 1998, p.295).

A Responsabilidade Social pode ser entendida de diferentes perspetivas. Pode representar a ideia de responsabilidade coletiva, uma imposição normativa legal e um comportamento coletivo responsável no sentido ético. Esta última conceção centra-se no pressuposto de que, uma atitude responsável pressupõe um procedimento ético. Na prática, a responsabilidade social e ambiental tende a ser transformada quer numa contribuição bondosa de conceção filantrópica quer num suporte de imagem das organizações. A responsabilidade social e ambiental referese à ética como procedimento condutor das ações com todos os públicos com os quais a organização pode interagir ou seja, os seus stakeholders sociais (comunidade, governo, entidades reguladoras, organizações com fins não lucrativos e Organizações Não Governamentais - ONGs e meio ambiente), os seus 


\section{Responsabilidade Social e Ambiental das Empresas. Uma perspectiva sociológica.}

stakeholders económicos (os clientes, financiadores, distribuidores e fornecedores) e os seus stakeholders organizacionais (colaboradores, gestores, acionistas e sindicatos) (Werther e Chandler, 2006).

Neste artigo, defendemos um conceito de responsabilidade social e ambiental mais amplo, baseado na perspetiva sociológica construtivista (Berger e Luckmann, 1999; Giddens, 2003; Morgan, 2006). A realidade social é externa ao sujeito ou é resultado da consciência individual? Segundo estes autores, a relação entre o indivíduo, como produtor e o mundo social, produto dele, deve ser uma relação dialética, isto é, o indivíduo no seu contexto social e o seu mundo social reagem mutuamente um sobre o outro. $\mathrm{O}$ produto age sobre o produtor e viceversa. A realidade surge da relação com o outro e é impossível construir uma realidade sem ter contato com o outro. A socialização acontece sempre através de uma contextualização de uma estrutura social particular.

Adotamos o conceito de responsabilidade social e ambiental assente em três dimensões: 1. A dimensão do conhecimento ambiental/informação; 2. A dimensão das práticas, estratégias, preocupações ecológicas; 3. A dimensão simbólica (atitudes e valores). Apresentamos os resultados de um estudo exploratório em cinco empresas do Norte de Portugal, na região do Ave. Sendo que três estão certificadas, uma em processo de certificação e outra não certificada, e que afirma não estar nos seus planos a certificação.

Verificamos que a Responsabilidade Social e Ambiental direcionadas para as empresas são apercebidas apenas como qualidade e fortalecimento tanto da marca como da imagem da empresa. Deste modo, os agentes sociais das empresas sublinham ainda a relevância da diferenciação perante a concorrência e a fidelização de clientes, a segurança patrimonial e a dos funcionários, a atração e retenção de talentos profissionais, a proteção contra ação negativa de funcionários, a menor ocorrência de fiscalização e auditoria por órgãos externos e, por fim, a atração de investidores e as deduções fiscais.

Este artigo encontra-se estruturado em quatro partes. Na primeira, apresentamos as diferentes perspetivas de responsabilidade social e ambiental. $\mathrm{Na}$ segunda, os processos de regulação. Na terceira, explicitamos a metodologia. Por fim, na parte empírica, analisamos os resultados.

\section{A concetualização da responsabilidade social e ambiental.}

A ideia de devolução de uma parte das mais-valias das empresas à sociedade, em forma de caridade e solidariedade tem origem nos filantropos dos finais do século XIX. Todavia, é nos anos cinquenta que emerge o primeiro conceito de responsabilidade social. Em 1953, Howard Bower é o primeiro a tentar definir a responsabilidade social como sendo as obrigações dos homens de 
Maria Paula Vilhena Mascarenhas

Cristiana dos A. Fernandes Costa

negócios em incorporar nas suas decisões linhas de ação compatíveis com os fins e valores da nossa sociedade (Neves e Silva, 2009, p. 8). O agravamento dos problemas ambientais à escala mundial levou a uma crescente sensibilização da necessidade de conciliar o desenvolvimento económico e a preservação ambiental, duas questões que antes eram tratadas separadamente e, que hoje, se encontram unidas numa só designação: o desenvolvimento sustentável. Em prol do desenvolvimento sustentável, a legislação ambiental tem-se tornado, paulatinamente, mais restritiva, exigindo uma regulação e uma responsabilização social por danos ambientais. Simultaneamente, tem-se assistido a uma crescente pressão social para que as empresas, um dos principais agentes poluidores, tenham a perceção dos impactos negativos das suas atividades sobre o meio ambiente. Acrescenta-se ainda, um movimento social emergente de procura de produtos "ecologicamente corretos". Os motivos estes que induziram as empresas a assumir uma postura mais responsável quanto à questão ambiental, marcando a emergência e a proeminência do conceito de Responsabilidade Social Empresarial (RSE).

Como referimos, a responsabilidade social e ambiental pode ser entendida de diferentes perspetivas. Pode representar a ideia de responsabilidade coletiva, uma imposição normativa legal e um comportamento coletivo responsável no sentido ético. Esta última conceção centra-se no pressuposto de que, uma atitude responsável pressupõe um procedimento ético. $\mathrm{Na}$ prática, a responsabilidade social e ambiental tende a ser transformada quer numa contribuição bondosa de conceção filantrópica num suporte de imagem das organizações. O ambiente seria reconhecido como um «lugar determinado ou percebido no tempo onde os elementos naturais e sociais estão presentes em relações e em interação» (Reigota, 1995, p.14).

Mais recentemente, no que concerne a responsabilidade social, Schwartz e Carrol (2007) propõem um modelo assente nos VBA (valor, balance, accountability) que congrega os conceitos de responsabilidade social das empresas, da cidadania corporativa, da sustentabilidade, da gestão dos stakeholders e da ética das empresas. Os autores argumentam que o modelo VBA contribui para analisar e relacionar as dimensões tais como a gestão estratégica e a corporate governance.

No nosso entendimento, a responsabilidade social e ambiental pressupõe a construção social de um conceito amplo e multidimensional que englobe outros conceitos tais como cidadania corporativa, desenvolvimento sustentável, crescimento sustentável, sustentabilidade, filantropia empresarial, ética empresarial, marketing social, ativismo social empresarial. Deste modo, definimos

${ }^{1}$ VBA = valor, equilíbrio, responsabilização - tradução nossa.

Latitude, vol. 7, n`2, pp.141-167, 2011. 


\section{Responsabilidade Social e Ambiental das Empresas. Uma perspectiva sociológica.}

responsabilidade social e ambiental como um processo contínuo, progressivo e voluntário que congrega, por um lado, a competência da empresa em cooperar e interagir com a comunidade sobre questões sociais e ambientais, levando em consideração os seus valores e atitudes para atingir os seus objetivos e, por outro lado, envolve tanto processos de regulação tais como as normas, a gestão dos stakeholders e da ética empresarial, o marketing social e os rótulos sociais e ecológicos como processos de execução de obrigações ambientais legais. Deste modo, a responsabilidade social e ambiental desencadeia processos de socialização ecológica e ética, de solidariedade social e ambiental tanto por parte dos agentes sociais da empresa como dos sujeitos que são simultaneamente cidadãos e consumidores.

A responsabilidade social e ambiental exige das empresas uma mudança assente em três paradigmas: o económico, o ambiental e o social. No domínio ambiental, a RSE tem passado cada vez mais pela integração voluntaria das preocupações ambientais na estratégia empresarial, através da implementação de Sistemas de Gestão Ambiental (SGA) e da sua certificação de acordo com as normas internacionais ISO 14001 e/ou europeias EMAS, bem como pela elaboração e divulgação de informação sobre a atuação, a performance e os impactos ambientais das atividades empresariais.

De forma a compreender a envolvente desta norma ambiental, apresentamos as definições de ambiente e de Sistema de Gestão ambiental -SGA constantes na Norma NP EN ISO 14001, 2004. O conceito de ambiente expresso nesta Norma define-se por "Envolvente na qual uma organização opera incluindo o ar, a água, o solo, os recursos naturais, a flora, a fauna, os seres humanos e suas inter-relações". O conceito de Sistema de Gestão Ambiental (SGA) é definido como "Parte do sistema de gestão de uma organização utilizada para desenvolver e implementar a sua política ambiental e gerir os seus aspetos ambientais".

Os objetivos de um Sistema de Gestão Ambiental são a promoção da proteção ambiental e a prevenção da poluição, em equilíbrio com as necessidades socioeconómicas (NP EN ISO 14001, 2004). Todavia, segundo Georg Winter (1992), a economia europeia só poderá levar a cabo a sua nova tarefa de contribuir de modo decisivo para a reconstrução do ambiente devastado se as empresas individualmente estiverem preparadas para adotar o princípio da gestão ambiental.

A reabilitação e revalorização das empresas e das suas funções encontram-se indissociavelmente aliadas à crise económica e social sentida nos países ocidentais, a partir da década de 70 do século $X X$, e pela promoção de que as empresas constituem um espaço (re) produtor de valores, colocando em evidência novos objetos de análise, tais como as problemáticas da identidade, da cultura, da mudança, do ambiente, entre outras. 
Maria Paula Vilhena Mascarenhas

Cristiana dos A. Fernandes Costa

De acordo com a sociologia das organizações, a empresa é definida enquanto instituição no sentido durkheimiano de orientação normativa e integrada das ações individuais. É um lugar coletivo onde os indivíduos estão submetidos a normas, regras e valores que, pela legitimidade de que desfrutam, unem os grupos e estruturam as relações sociais. A dominação social daqui consequente exerce-se na medida em que, apesar dos conflitos e tensões sempre existentes no seio das instituições, tende a predominar uma conciliação, ainda que impositiva e mais ou menos desigual, entre os interesses dos sujeitos e os interesses gerais da empresa. Tal conciliação aproxima, pelo menos parcialmente, os sujeitos da coletividade, garantindo a partilha de um conjunto de sentimentos, ideias e normas, produzindo efeitos integradores de socialização, ainda que, muitas vezes, contra a vontade dos sujeitos.

Deste modo, a empresa é, consequentemente, definida como instituição cultural e simbólica. As experiências de trabalho quotidiano estão na origem de um processo de socialização secundário que propõe aos sujeitos a participação em relações interpessoais e em rituais de iniciação, de acolhimento e de manutenção da solidariedade grupal. Tais práticas estabelecem ocasiões de aprendizagem social, contribuindo para a criação de modos comuns de apreender o mundo e de viver em sociedade.

De forma a «superar as antigas tradições organizacionais do trabalho em benefício do desenvolvimento da autonomia, da participação e da iniciativa dos sujeitos e dos grupos, [esta] exige uma transformação difícil porque de sinal contrário à herança gestionária e à dinâmica assalariada que a caracteriza, continuam [a persistir] as relações sociais de produção da sociedade salarial» (Sainsaulieu, 1997, p.19). Dado que, esta adaptação se impõe por razões económicas, crê-se na sua possibilidade de realização a longo prazo. A esta situação associa-se a outra que se traduz na capacidade das empresas integrarem explicitamente nas suas culturas coletivas as diferentes caraterísticas dos sujeitos e dos grupos que as integram. Trata-se agora de atender a estas forças distintas, as microculturas e os projetos autónomos de grupos e unidades funcionais ou orgânicas diferenciadas, de modo a promover formas de integração coletiva através de projetos transversais e da produção de uma linguagem comum. Aqui também as tradicionais relações de autoridade, subordinação e controlo são questionadas e redefinidas pelo «reconhecimento das interdependências entre autonomias de base» (Sainsaulieu, 1997, p. 20). A mudança, caraterística permanente do mundo, é outro dos problemas que se coloca ao desenvolvimento económico e social das empresas. Implica que estas se movam de acordo com uma lógica organizacional e de gestão capaz de lidar com a incerteza e, consequentemente, com as diretrizes das previsões, que substituem a anterior situação de estabilidade. A flexibilidade e a capacidade de aprendizagem para lidar com um futuro incerto e desconhecido contrariam as práticas clássicas

Latitude, vol. 7, n², pp.141-167, 2011. 


\section{Responsabilidade Social e Ambiental das Empresas. Uma perspectiva sociológica.}

habituais pautadas pela rotina, rigidez e permanência e predispõem as empresas a flexibilizar quantitativamente o emprego e a gerir os recursos humanos numa lógica individualizada e meritocrática.

No seio de casa empresa, as divergências entre grupos com lógicas socioeconómicas e culturais diferentes tendem, deste modo, a agudizar-se, exigindo uma «dinâmica de negociação, de diálogo e de compromisso entre lógicas divergentes» (Sainsaulieu, 1997, p. 21).

De fato, um outro problema e, talvez o que mais nos suscita interesse, referese às contradições que as empresas têm de gerir nas relações entre o trabalho e a sociedade. Questiona-se, deste modo, todo um conjunto de situações contraditórias que se traduzem, nomeadamente, na possibilidade de conciliar a motivação dos indivíduos com a constante ameaça de redução de efetivos ou de criar uma cultura de responsabilidade coletiva quando se opta por uma lógica individualista de gestão das carreiras ou, ainda, de garantir a seleção dos melhores sem excluir os menos aptos. Estes aspetos ajudam a questionar a legitimidade absoluta das empresas como vetor identitário, novos vetores de identificação se afirmam, surgindo uma ambivalência de sentimentos face ao valor do trabalho e do emprego na vida dos sujeitos e, consequentemente, da sua dedicação à atividade profissional.

Postula-se, contudo, hoje, que por razões de melhoria do desempenho económico, é imprescindível a adoção de um paradigma cooperativo em detrimento do conflitual, tendo a imputar-se paralelamente à empresa uma responsabilidade social e ambiental decorrente do seu papel institucional contemporâneo.

A responsabilidade social e ambiental das empresas pressupõe a capacidade das mesmas para responderem às necessidades e às expectativas da sociedade em geral. Porém, trata-se de uma integração voluntária de preocupações sociais e ambientais por parte das empresas nas suas operações e na sua interação com outras partes interessadas (Livro Verde da Comissão Europeia, 2001). Ainda que o objetivo primeiro das empresas seja a obtenção de rentabilidade económica, pretende-se que a possam atingir a favor da sociedade, isto é, que possam contribuir, simultaneamente, para o cumprimento dos objetivos sociais e ambientais, mediante a integração destes na sua estratégia. Nesta ótica, «há uma preocupação com as interações desenvolvidas entre as empresas e a sociedade, assumindo aquelas a sua «razão de ser» de uma forma mais abrangente intimamente associada à sociedade envolvente e ao impacto que nela provoca. Emerge a necessidade de um compromisso entre aquilo que os dirigentes pretendem e aquilo que a sociedade tem direito de exigir, nomeadamente em termos de responsabilidades específicas tais como a ecologia, o emprego de minorias, de deficientes entre outras» (Parente, 1995, p. 90-91). 
Maria Paula Vilhena Mascarenhas

Cristiana dos A. Fernandes Costa

A responsabilidade da empresa é operacionalizada a dois níveis de atuação: 1. O domínio interno das empresas; 2 . O domínio externo. O primeiro, remete para as práticas socialmente responsáveis que implicam o investimento no capital humano, nomeadamente em termos de formação, de motivação organizacional, de comunicação e informação, de conciliação entre a vida profissional e familiar dos trabalhadores, de diálogo social, de saúde, de higiene e segurança no trabalho, de gestão da mudança, de gestão dos recursos naturais e dos impactos ambientais. O segundo, «designado igualmente por cidadania empresarial" (Neves e Rodrigues, 2003 , p. 4) remete para a extensão da intervenção das empresas na comunidade local, ao envolver os trabalhadores, os stakeholders sociais (comunidade, governo, entidades reguladoras, organizações locais sem fins lucrativos e organizações Não Governamentais - ONGs), os stakeholders económicos (os clientes, financiadores, distribuidores e fornecedores) e os stakeholders organizacionais (colaboradores, gestores, acionistas e sindicatos) (Werther e Chandler, 2006). Em Portugal, a responsabilidade social e ambiental tem adquirido maior visibilidade devido «às estratégias de enriquecimento de imagem institucional e de marketing social das empresas que a praticam» (Neves e Rodrigues, 2003, p. 12).

Em síntese, não existe consenso universal na definição de responsabilidade social e ambiental das empresas. Contudo, ela emerge de uma atitude ética das empresas perante a sociedade e o ambiente. Em seguida, apresentamos os processos de regulação a responsabilidade social e ambiental.

2. Os processos de regulação: as normas, o marketing social e os rótulos sociais e ecológicos

Comparar e utilizar conceitos como marketing social, normas e rótulos sociais e ecológicos, colocando-os "frente a frente", não é simples, uma vez que todos remetem para uma causa social/ambiental. No entanto, os seus objetivos/fins são diferentes, pois o marketing social deixa bem visível o objetivo de estimular o negócio/mercado, através de uma imagem positiva. As normas e os rótulos pressupõem a visão de uma empresa que consome em benefício próprio (direta ou indiretamente) recursos naturais renováveis ou não, pertencentes à sociedade, $\mathrm{e}$ nesse sentido contraí uma dívida para com a comunidade. Tornando-se num mecanismo de compensação.

Neste sentido, a nossa interpretação da responsabilidade social e ambiental, em termos de processos de regulação, passa pelo debate entre a performance ambiental e a performance económica.

As normas de Gestão Ambiental

Latitude, vol. 7, n², pp.141-167, 2011. 


\section{Responsabilidade Social e Ambiental das Empresas. Uma perspectiva sociológica.}

As Normas da série ISO 14000 são normas de gestão ambiental e a sua utilização apresenta vantagens. As Normas ISO 14001 e ISO 14004 aplicam-se a SGAs, podendo ser utilizadas como ferramentas para ajudar a organização a definir e atingir a sua política ambiental, objetivos e metas (ISO, 2005). Estas normas foram publicadas em 1996 apesar da versão portuguesa da ISO 14001 tivesse sido publicada três anos mais tarde, em 1999. Em Novembro de 2004, foram substituídas pelas versões ISO 14001, 2004 (NP EN ISO 14001, 2004) - Sistemas de Gestão Ambiental - Requisitos e linhas de orientação para a sua utilização e ISO 14004, 2004 - Sistemas de Gestão Ambiental - Linhas de orientação em princípios, sistemas e técnicas de suporte.

A Norma ISO 14001 define requisitos para SGAs e fornece uma base de trabalho para uma aproximação estratégica e sistemática à política, planos e ações da organização, o que permite estabelecer uma linguagem comum para comunicar acerca de questões relacionadas com a gestão ambiental com clientes, fornecedores ou outras partes interessadas. A Norma ISO 14001 requer que a organização melhore o seu desempenho ambiental continuamente e suporta-a na definição do caminho a seguir e na forma como controla os seus impactes ambientais negativos (NP EN ISSO 14001, 2004), e não define propriamente valores/parâmetros de desempenho a atingir, contudo é requerido um compromisso de cumprimento dos requisitos legais aplicáveis e outros aplicáveis aos aspetos ambientais e um compromisso de prevenção da poluição (ISO, 2005; NP EN ISO 14001, 2004).

$\mathrm{Na}$ última década, desenvolveu-se um conjunto de instrumentos que visam uma melhoria da gestão dos recursos naturais e a diminuição dos impactos ambientais das atividades humanas, tendo em vista uma racionalização dos recursos, um melhor controlo e inovação dos processos produtivos e sobretudo uma mudança profunda da perceção e consciencialização dos problemas, aguardando uma inferência na alteração comportamental a nível individual e da organização das organizações.

Esta abordagem subentende uma atitude interventiva e uma melhoria contínua do desempenho ambiental das empresas. Um bom desempenho ambiental é visto como um fator de competitividade das empresas, em consequência de uma gestão mais racional das matérias-primas, da energia, da redução e o correto tratamento dos resíduos. Com isto, a redução em termos de matérias-primas e energia, bem como a redução das despesas com os tratamentos dos resíduos resultado de um maior controlo do processo produtivo, originam um aumento da competitividade das empresas.

A Gestão Ambiental é composta por um conjunto de medidas conducentes à redução dos impactos ambientais negativos, e por um processo de auditoria que certifica o bom desempenho ambiental através da atribuição de um certificado que assegura a qualidade e um bom desempenho do produto/serviço/processo 
Maria Paula Vilhena Mascarenhas

Cristiana dos A. Fernandes Costa

produtivo (Valle, 1995, p. 16). Este certificado estabelece uma segurança de um bom desempenho para os clientes, consumidores e sociedade em geral.

Deste modo, a gestão ambiental visa a qualidade ambiental ou o equilíbrio entre as atividades da empresa e o ecossistema onde tais atividades se inserem. A qualidade ambiental, envolve o ciclo de vida do produto, o tratamento dos efluentes e de qualquer outro fator que afete a vizinhança das instalações da empresa.

\section{O Marketing social}

Esta ligação entre comunicação, visibilidade e compromisso leva-nos a julgar que as ações empresariais de intervenção social podem ser olhadas apenas como marketing social.

A responsabilidade social e ambiental das empresas «tem sido disseminada entre várias empresas, através de instrumentos como selos, certificações e a divulgação pelos meios de comunicação social das ações sociais de empresas responsáveis. Para a difusão dessas ações sociais as organizações podem lançar mão do Marketing Social, que tem um caráter fundamental para a formação da imagem da instituição» (Levek et al., 2002, p. 20).

O marketing social é definido como "um processo social por meio do qual pessoas e grupos de pessoas obtêm aquilo de que necessitam e o que desejam com a criação, oferta e livre negociação de produtos e serviços de valor com outros" (Kotler, 2000, p. 30).

Deste modo, segundo Kotler, o marketing social é definido como "o projeto, a implementação e o controle de programas que procuram aumentar a aceitação de uma ideia social num grupo-alvo. Utiliza conceitos de segmentação de mercado, de pesquisa de consumidores, de configuração de ideias, de comunicações, de facilitação de incentivos e a teoria da troca, a fim de maximizar a reação do grupoalvo" (1978, p. 287)

O marketing social é uma estratégia para a alteração de comportamentos, combinando os melhores componentes das abordagens tradicionais de mudança social num esquema integrado de planeamento e ação aproveitando os avanços na tecnologia das comunicações e na própria capacidade de marketing. Segundo Thompson e Pringle (2000), «o marketing para as causas sociais pode ser definido como uma ferramenta estratégica de marketing e de posicionamento que associa uma empresa ou marca a uma questão ou causa social relevante, em benefício mútuo» (2000, p. 3).

O marketing social pode ser entendido como um plano de mudanças comportamentais e de atitudes, que pode ser utilizado em qualquer tipo de instituição, desde que esta tenha uma meta final a produção e a transformação de 


\section{Responsabilidade Social e Ambiental das Empresas. Uma perspectiva sociológica.}

impactos sociais. Assim a empresa beneficia de uma imagem vinculada a uma causa social trazendo uma visibilidade perante o seu público e mercado.

De fato, Melo Neto e Froes (2001) defendem que:

"O verdadeiro marketing social atua fundamentalmente na comunicação (...), com ações que visam aumentar comprovadamente o seu bem-estar social e o da comunidade. Essas ações de médio e longo prazo garantem sustentabilidade, cidadania, solidariedade e coesão social (...) a empresa ganha produtividade, credibilidade, respeito, visibilidade e, sobretudo, vendas maiores" (Melo Neto e Froes, 2001, p. 74).

Com base nestas informações podemos ter um indício que os indivíduos apoiam as atitudes das organizações envolvidas numa causa social, estando inclusive dispostas a pagar um preço mais elevado por um determinado produto vinculado a uma razão social, sendo estes produtos mais convincentes que os produtos que não apoiam uma causa social.

Deste modo e, em jeito de conclusão, as empresas procuram mais-valia na responsabilidade social e ambiental tais como o reforço da marca e de sua imagem e, consoante os resultados dos projetos sociais por estas financiados, as organizações empresariais podem tornar-se conhecidas do público e aumentar os seus lucros. Deste modo, a marca, os produtos e os serviços adquirem maior visibilidade. Os clientes consumidores cada vez mais conscientes das questões sociais e ecológicas preferem e sentem orgulho em comprar produtos e contratar serviços de uma empresa com um grande sentido de responsabilidade social e ambiental, um ethos social e ecológico.

Como resultado final, a longo prazo, as empresas podem obter um aumento nas vendas, e assim, fortalecer a imagem, o respeito e confiança, assegurando a sua auto-preservação.

\section{Os Rótulos sociais e ecológicos}

Segundo o Livro Verde da Comissão das Comunidade Europeias (2001), alguns inquéritos comprovaram que os compradores desejam produtos seguros e de qualidade, mas também impõem saber se eles são fabricados de forma socialmente responsável. Grande parte dos consumidores europeus declara que o compromisso de uma empresa com a sua responsabilidade social e ambiental é um fator que pesa na aquisição de um produto ou serviço. Este aspeto cria oportunidades de mercado atraentes, porque um número significativo de consumidores estaria predisposto a pagar mais por produtos correspondentes aos princípios da responsabilidade social e ambiental, embora, atualmente, apenas uma minoria o faça. "As questões que mais preocupam os consumidores europeus 
Maria Paula Vilhena Mascarenhas

Cristiana dos A. Fernandes Costa

são a proteção da saúde e da segurança dos trabalhadores e o respeito dos direitos humanos em todas as operações de uma empresa e na sua cadeia de produção (sem recurso, por exemplo, ao trabalho infantil), a defesa do ambiente em geral e a redução das emissões de gases que contribuem para o efeito de estufa em particular" (Livro Verde da Comissão das Comunidade Europeias, 2001).

De forma a solucionar o aumento do nível de exigência dos consumidores em relação à responsabilidade social e ambiental das empresas, emergiram os "rótulos sociais", criados por fabricantes individuais (marcas autodeclaradas) ou setores de atividade, ONG e governos. Mais do que instrumentos reguladores, trata-se de incentivos baseados no mercado, passíveis de provocarem uma evolução social positiva entre empresas, retalhistas e consumidores" (Livro Verde da Comissão das Comunidade Europeias, 2001).

Deste modo, a extensão desta aplicação e o impacto potencial das iniciativas de rotulagem social são ainda limitados, dado que incidem em setores específicos do mercado retalhista. Os rótulos sociais são sobre os produtos importados e apenas atingíveis a consumidores com maior poder de compra. Esta limitação faz com que a quota de mercado dos produtos que ostentam um rótulo social continua a ser reduzida apesar de ter aumentado nos últimos anos o que comprova a necessidade de melhorar a eficácia destes rótulos.

Os "rótulos sociais" são referência de uma garantia de produção de um determinado artigo isento de qualquer exploração ou abuso. No entanto, pecam por falta de transparência e de verificação independente. Ao contrário do que acontece com os rótulos relativos à composição ou à segurança de um produto, essas alegações não podem ser verificadas através da realização de testes ao próprio produto. Para os rótulos sociais serem credíveis, seria necessária uma verificação constante dos locais de trabalho, executada segundo normas acordadas" (Livro Verde da Comissão das Comunidade Europeias, 2001).

Apesar destes constrangimentos, a multiplicação dos sistemas de rótulos sociais poderá mostrar-se prejudicial em termos da sua eficácia, tendo em conta a confusão que podem gerar nos consumidores as divergências provocadas pela diversidade de critérios utilizados e a falta de clareza entre os vários rótulos. $\mathrm{O}$ mercado "verde" torna-se cada vez mais consolidado por causa da crescente procura de produtos não prejudiciais ao meio ambiente. Contudo, não se pode evitar o crescimento paralelo de muitas atribuições ecológicas duvidosas e enganosas, facilitando o disfarce da verdade sobre produtos que, desta forma, confundem os consumidores.

Verificamos, ainda, a necessidade crescente de uma discussão em relação ao valor e à pertinência ou seja, no âmbito do mercado interno e das obrigações internacionais e também nas ações públicas destinadas a aumentar a eficácia dos rótulos sociais e ecológicos. A título de exemplo, o Livro Verde da Comissão das Comunidades Europeias (2001) propôs um conjunto de ações de formação e 


\section{Responsabilidade Social e Ambiental das Empresas. Uma perspectiva sociológica.}

sensibilização sobre as condições de trabalho, a promoção de melhores práticas através do patrocínio de prémios às empresas, o fomento da criação de parcerias que envolvam diversas partes interessadas, o desenvolvimento de normas de rotulagem social e o recurso a contratos públicos e incentivos fiscais de forma a promover os produtos rotulados.

Deste modo, os rótulos ambientais ou ecológicos são instrumentos de cooperação na implementação de políticas públicas em vista de uma mudança de consumo, isto é, um desenvolvimento de novos padrões de consumo que resultem em condições ambientalmente mais saudáveis e possam contribuir para uma evolução da produção industrial.

\section{Metodologia}

O método utilizado foi o hipotético dedutivo e a nível empírico, o método comparativo de forma a salientar as diferenças entre os cinco casos estudados. A metodologia utilizada numa investigação está relacionada com a realidade que se pretende compreender ou seja a responsabilidade social e ambiental das empresas a partir da análise das práticas e atitudes ambientais dos agentes sociais.

Neste contexto, sendo um estudo de tipo preliminar, valorizámos fundamentalmente tanto os aspetos mais objetivos, isto é, as práticas declaradas, as práticas reconstruídas e as normas relacionadas com o sistema de gestão ambiental como aspetos subjetivos ligados às representações ambientais (atitudes e valores) da empresa.

A escolha técnico-metodológica incidiu primeiramente sobre a pesquisa e análise bibliográfica referente ao objeto em estudo, à natureza do fenómeno, à diversidade e complexidade que o próprio problema descreve e a pesquisa e análise documental de um conjunto de documentos legislativos. Numa segunda fase, optámos pela entrevista semiestruturada, aplicada aos responsáveis pela certificação ambiental no caso das empresas certificadas pela NP ISO 14001, 2004; no caso das empresas não certificadas ambientalmente as entrevistas foram aplicadas aos responsáveis pela área da certificação de qualidade e segurança, isto porque, para além destas certificações terem normas em comum com a certificação ambiental, estes responsáveis também têm a seu cargo a implementação de práticas ambientais na empresa.

Todas as entrevistas decorreram dentro das instalações das empresas, aos responsáveis pelo departamento de ambiente ou qualidade das respetivas empresas. Os entrevistados acederam a colaborar na pesquisa, mas apenas respondendo cordialmente e formalmente ao que lhes era perguntado. $\mathrm{O}$ ambiente foi de relativa liberdade, apesar de se notar formalidade no discurso dos entrevistados. Estes não se esquivaram às questões colocadas, havendo apenas alguns assuntos, nomeadamente as práticas ambientais, sobre os quais nem sempre 
Maria Paula Vilhena Mascarenhas

Cristiana dos A. Fernandes Costa

havia grande fluidez de conversa, talvez por estas práticas incluírem as normas da ISO 14001, 2004.

As entrevistas tiveram um suporte áudio, à exceção de uma delas dado que não foi possível utilizar o micro gravador, por motivo de recusa da entrevistada. Assim sendo, a entrevista decorreu sem suporte digital. De forma a solucionar o problema e possíveis enviesamentos, a entrevistada procedeu posteriormente à leitura e correção das respostas.

Deste modo, a análise de conteúdo do Corpus documental e das entrevistas desencadeou-se mediante um processo simplificado, baseado numa análise comparativa através da construção de categorias e análises temáticas. Pretendemos assim descrever situações e interpretar o sentido do que nos foi dito.

\section{O Universo e a amostra}

Escolhemos a cidade de Guimarães, inserida na região do Vale do Ave, pela sua especificidade mas também pela facilidade de contato com a população empresarial em estudo.

O Vale do Ave surge em segundo lugar na Região Norte no que concerne ao número de empresas, isto é, cerca de 42000 e ao emprego nos setores secundário e terciário, cerca de 180000 pessoas. Tem uma taxa de população ativa na ordem dos $51,8 \%$, um pouco mais alta que a da Região Norte $(48,1 \%)$ e que a média nacional $(48,2 \%)$. Esta Região do Vale do Ave é marcada por um elevado nível de industrialização, e concentra a sua atividade, essencialmente, nas indústrias têxteis e de vestuário.

De modo a construir a amostra, selecionámos cinco empresas inseridas no concelho de Guimarães, da região do Vale do Ave. Este critério de escolha mostrase pertinente devido ao esforço existente em despoluir o Rio Ave. As cinco empresas têm diferentes atividades: têxtil, metalomecânica, acabamentos de fios, tecidos e artigos têxteis, lavandaria e tinturaria e, por último, fabricação de equipamentos não-domésticos de refrigeração e ventilação.

Esta opção deveu-se ao facto de primeiro ser uma pesquisa qualitativa e utilizarmos uma amostragem por caso múltiplo, ou seja, amostragem por contraste "é comparar situações extremas (...) pelo menos duas de cada grupo pertinente para o objeto de pesquisa" (Guerra, 2006, p. 45). Assim sendo, decompor os perfis da amostra revela-se importante na perceção do peso da sensibilidade ambiental na certificação NP ISO 14001, 2004. Relativamente à questão da certificação ambiental, poder-se-á dizer que a área de atividade da empresa influencia a opção pela certificação ambiental, como é o caso da entrevista $n^{\circ}$ 3, que afirma que não está nos planos da empresa a certificação ambiental, sendo a sua área de atividade a causa apontada: «Não, não é um objetivo, dado à nossa atividade, dado aos resíduos produzidos, portanto o valor acrescentado, a certificação não é de todo um objetivo» 


\section{Responsabilidade Social e Ambiental das Empresas. Uma perspectiva sociológica.}

(Entrevista no3). Realizámos entrevistas em cinco empresas, três certificadas pela norma ISO 14001, 2004, uma empresa em vias de certificação e outra em que a certificação ambiental não está nos planos da empresa.

\section{Modelo de análise}

A junção da dimensão das atitudes com as práticas na operacionalização da orientação ambiental sugere estabelecer um bom argumento metodológico. Pois as práticas declaradas (aquelas que as entrevistas permitem conhecer) podem não envolver sempre práticas efetivas, mas representam certamente boa indicação da orientação para a ação (Almeida et al, 2000, p. 338).

A análise tem em conta as práticas e as representações ambientais. Adotamos o conceito de responsabilidade social e ambiental assente em três dimensões: 1. A dimensão do conhecimento ambiental/informação; 2. A dimensão das práticas, estratégias, preocupações ecológicas; 3. A dimensão simbólica (atitudes e valores). No entanto, só as atitudes, os valores e as práticas serão operacionalizadas, uma vez que a dimensão da informação é analisada principalmente através da transmissão de informação ambiental entre atores sociais da empresa e o motivo subjacente a esta transmissão. Outro ponto importante na dimensão da informação é a procura e a disponibilidade de informação ambiental por parte destes atores sociais.

Defendemos neste trabalho que o conhecimento/informação ambiental se relacionam com a atitude ambiental. São uma parte das representações sociais e estão articuladas nas interações sociais. As atitudes ambientais são definidas com três modalidades: ativistas, ativos e simpatizantes.

Quadro 1: Modelo de Analise: Atitudes

\begin{tabular}{|c|c|c|}
\hline \multirow{4}{*}{ Atitud } & Dimensõe & Indicadores \\
\hline & Ativistas & $\begin{array}{l}\text { - Ações coletivas de defesa do ambiente; } \\
\text { - Valorização do ambiente no } \\
\text { desenvolvimento de novos produtos; } \\
\text { - Disposição favorável à participação de } \\
\text { uma melhoria do impacto ambiental da } \\
\text { empresa. }\end{array}$ \\
\hline & Ativos & $\begin{array}{l}\text { - Participação em ações coletivas ou } \\
\text { práticas quotidianas mas não de modo tão } \\
\text { consistente }\end{array}$ \\
\hline & Simpatiza & - Empresas que afirmam pontualmente \\
\hline
\end{tabular}


Maria Paula Vilhena Mascarenhas

Cristiana dos A. Fernandes Costa

\begin{tabular}{ll}
\hline ntes & desenvolverem práticas quotidianas ou \\
& participar em ações coletivas sem \\
& correspondência no plano dos valores e da \\
& mobilização.
\end{tabular}

Fonte: (Costa, 2011, p. 72)

Consideramos como ativistas os entrevistados que participam em ações coletivas de defesa do ambiente, desenvolvem práticas individuais quotidianas com incidência na preservação ambiental, valorizam o ambiente no setor de desenvolvimento de novos produtos ou serviços e mostram disposição favorável à participação de uma melhoria do impacto ambiental da empresa. Os ativos são os que ainda declaram participar na ação coletiva e nas práticas quotidianas, mas já não de modo tão consistente como no caso anterior. Contemplamos como simpatizantes as empresas que afirmam pontualmente desenvolver práticas quotidianas ou participar em ações coletivas sem correspondência no plano dos valores e da mobilização.

As dimensões das atitudes ambientais e, sobretudo, os indicadores aqui retidos estão longe de ser indiscutíveis e comportam limitações quer de cobertura do universo em análise, quer de homogeneidade de significação. $\mathrm{O}$ indicador de ação coletiva corresponde a perguntas infiltradas nas entrevistas sobre, por exemplo, mecanismos para a participação dos trabalhadores ao nível das preocupações ambientais, bem como as práticas de caráter voluntário.

As práticas quotidianas poderão ser determinadas, por exemplo, pela declaração da empresa em possuir programas de redução do consumo de água, energia, redução ou reciclagem de resíduos.

Quadro 2: Modelo de análise das práticas

\begin{tabular}{|c|c|c|}
\hline & Dimensões & Indicadores \\
\hline Prát & $\begin{array}{l}\quad \text { Práticas } \\
\text { inseridas na } \\
\text { Norma ISO } \\
\text { 14001:2004 }\end{array}$ & $\begin{array}{l}\text { - Elaboração e divulgação da política } \\
\text { ambiental perante funcionários e comunidade; } \\
\text { - Procedimentos que permitam identificar, } \\
\text { administrar e controlar os resíduos sólidos, } \\
\text { emissões atmosféricas e efluentes líquidos; } \\
\text { - Criação de um sistema de acesso às } \\
\text { exigências legais à sua atividade; } \\
\text { - Deter organograma } \\
\text { - Definição de um ou mais profissionais } \\
\text { para representar os assuntos específicos da } \\
\text { Gestão Ambiental, } \\
\text { - Formação dos funcionários na área } \\
\text { ambiental, quer nos seus impactos reais ou } \\
\text { potenciais associados às suas tarefas; } \\
\text { - Sistema de comunicados relativos às }\end{array}$ \\
\hline
\end{tabular}

Latitude, vol. 7, n², pp.141-167, 2011. 


\section{Responsabilidade Social e Ambiental das Empresas. Uma perspectiva sociológica.}

\begin{tabular}{cc}
\hline & questões ambientais; Criação de manual de \\
gestão ambiental; controle de documentos; & Controle operacional; \\
& - Monitorização e avaliação do \\
& desempenho ambiental. \\
& - Participação em ações coletivas; \\
Práticas & - Incentivo às práticas individuais fora da \\
Voluntárias & empresa; \\
& - Organizações de eventos de âmbito \\
& ambiental. \\
\hline
\end{tabular}

Fonte: (Costa, 2011, p. 73)

No plano das práticas retivemos um indicador das ações de defesa do ambiente a nível das práticas inseridas no plano de obrigatoriedade da Norma ISO 14001, 2004 e as práticas voluntárias com incidência na preservação do ambiente. Os bons fundamentos para acrescentar este argumento operativo não excluem, todavia, contrariedades de ordem variada. Se a significação de atitudes ambientais como tendências mais ou menos favoráveis à ascensão da qualidade do ambiente, observáveis na maior ou menor solidez entre valores, a disposição para a ação e as práticas declaradas parecem constituir uma base sólida de partida. A dificuldade teórica das dimensões pertinentes das atitudes ambientais requer elaboração autónoma; a presente prestação não vai muito além de uma experimentação tecnicamente fundamentada. Outra contrariedade genérica é a que decorre de ensaiarmos uma avaliação de atitudes ambientais nas empresas: a questão ambiental assume contornos de fenómeno emergente, a que se associa estruturação frágil de disposições e comportamentos e multiplicidade indefinida de perfis, o que permite apenas um esboço de tendências, principalmente no que se refere à análise social das atitudes ambientais.

A tipologia utilizada na avaliação dos valores terá duas modalidades, valores ecocêntricos e valores antropocêntricos.

Quadro 3: Modelo de análise dos valores

\begin{tabular}{|c|c|c|}
\hline \multirow{9}{*}{ Valores } & Dimensões & Indicadores \\
\hline & Antropocentrismo & - Ambiente como \\
\hline & (interesse próprio e & aspeto pouco ou nada \\
\hline & altruísmo & importante; \\
\hline & humanista) & - Organização, \\
\hline & & aspetos económicos como \\
\hline & & aspetos importantes ou \\
\hline & & muito importantes. \\
\hline & Ecocentrismo & - Ambiente como \\
\hline
\end{tabular}


Maria Paula Vilhena Mascarenhas

Cristiana dos A. Fernandes Costa

\begin{tabular}{ll}
\hline $\begin{array}{ll}\text { (altruísmo relativo à } \\
\text { biosfera) }\end{array}$ & $\begin{array}{l}\text { aspeto importante ou } \\
\text { muito importante. }\end{array}$ \\
\hline$\underline{\text { duas prioridades }}$ & $\begin{array}{l}\text { - Valores mistos } \\
\text { (conjugação entre } \\
\text { ambiente e produção } \\
\text { económica) }\end{array}$ \\
\hline
\end{tabular}

Fonte: (Costa, 2011, p. 75)

A visão "antropocêntrica" fundamenta-se na convicção de que o homem é um ser superior ao resto da "criação», visto ter sido concebido «à imagem e semelhança de deus»; esta ideia da superioridade humana foi sendo forçada ao longo dos séculos pelo desenvolvimento científico e técnico, que permitiu ao homem explorar com maior eficácia os recursos, libertando-o do «determinismo natural» e fundamentando o seu crescente controlo e domínio sobre a natureza. Mas esta visão está longe de ser a única. A visão "ecocêntrica" caracteriza-se, sobretudo, por considerar o ser humano como uma entre outras espécies que, embora possuindo cultura, tem uma relação forte com o mundo natural. Para além disto, postula que o mundo é finito e impõe limites físicos e biológicos ao crescimento económico, ao progresso social e a outros fenómenos societais.

Levantamos a seguinte hipótese: Uma melhor informação ambiental aliada a um esclarecimento sobre as questões gerais da ecologia (crenças) estão associadas a atitudes e práticas mais amigas do ambiente por parte dos empresários.

\section{A análise dos resultados}

O mercado "verde" torna-se cada vez mais consolidado por causa da crescente procura de produtos que não prejudiquem o meio ambiente. Deste modo, os rótulos ambientais através da certificação são instrumentos capazes de cooperar na implementação de políticas em proveito do desenvolvimento sustentável e de novos padrões de consumo resultantes de práticas ambientalmente mais saudáveis que, por sua vez, estimulam uma produção industrial mais responsável social e ambientalmente.

Sem dúvida que esta procura por rótulos amigos do ambiente influencia bastante a busca pela certificação ambiental. São os novos padrões de consumo que obrigam os produtores a integrarem práticas amigas do ambiente nos seus processos de produção. Todos os dias nos deparamos com produtos "verdes" no mercado, mas será que esta produção é sinónimo de uma preocupação ambiental das empresas ou um novo mercado de consumidores ambientalmente conscientes? A resposta inicialmente parecia simples mas no decorrer da investigação revelouse bastante dúbia, pois as certezas não se constituem apenas em base das práticas declaradas. Quando conjugamos estas práticas com algumas afirmações dos entrevistados facilmente percebemos que a questão económica ainda é fator predominante nas escolhas produtivas. Não conseguimos afirmar com clareza o 


\section{Responsabilidade Social e Ambiental das Empresas. Uma perspectiva sociológica.}

que está subjacente às práticas ambientais, apenas indícios de uma nova mentalidade empresarial, provocada por um mercado mais exigente. Apenas conseguimos afirmar que qualquer tentativa de alterar comportamentos exige uma mudança fundamental dos valores e da atitude dos gestores.

Entre as diversas exigências contestadas pela sociedade moderna, que interferem com a atividade empresarial, a preocupação ambiental tem ganho projeção significativa face à sua relevância para a qualidade de vida das populações. Como consequência destas pressões no seio de muitas empresas, sobre os problemas ambientais, o meio ambiente passa a fazer parte de um quadro de ameaças ou oportunidades, capazes de pôr em causa a permanência das empresas no mercado.

Em prol do desenvolvimento sustentável, a legislação ambiental tem-se tornado, paulatinamente, mais restritiva, exigindo uma regulação e uma responsabilização pelos danos ambientais. Simultaneamente, temos assistido a uma crescente pressão social para que as empresas, um dos principais agentes poluidores, tenham a perceção dos impactos negativos das suas atividades sobre o meio ambiente. Acrescentando-se ainda, um movimento social emergente de procura de produtos "ecologicamente corretos".

Estes motivos induziram as empresas a assumir uma postura mais responsável quanto à questão ambiental. Esta nova realidade passa cada vez mais pela integração voluntária das preocupações ambientais na estratégia empresarial, através da implementação de Sistemas de Gestão Ambiental (SGA) e da sua certificação de acordo com as normas internacionais ISO 14001 e/ou europeias EMAS, bem como pela elaboração e divulgação de informação sobre a atuação, a performance e os impactos ambientais das atividades empresariais.

Assim, a economia só poderá levar a cabo a sua nova tarefa de contribuir de modo decisivo para a reconstrução do ambiente devastado se as empresas, individualmente, estiverem preparadas para adotar o princípio da gestão ambiental.

Posto isto, a questão da performance ambiental e a performance financeira torna-se num ponto de referência. É claramente aceite que as boas práticas de gestão ambiental e os investimentos conducentes a uma melhor performance ambiental são benéficos para a empresa assim como para a sociedade. No entanto, estes investimentos representam custos que se transformam em conflitos de escolha. As posições que verificamos nos entrevistados são várias, pois se para uns os investimentos no aperfeiçoamento da performance ambiental representam custos às empresas, traduzindo-se na forma de preços elevados para os consumidores, desvantagens competitivas perante a concorrência e consequentemente menor retorno de lucro para a empresa. E nesta perspetiva, os investimentos ambientais são vistos como custos extra para as empresas, levando- 
Maria Paula Vilhena Mascarenhas

Cristiana dos A. Fernandes Costa

os a minimizar os custos discricionários, isto é, os gastos ambientais que não são expressamente exigidos pela lei.

Para outros, a melhoria da performance ambiental é uma potencial fonte de vantagens competitivas, na medida em que poderá resultar em menores custos de produção, bem como os custos relacionados com o incumprimento da legislação ambiental, originando novas oportunidades de mercado. Assim, através do uso mais eficiente de recursos, o reaproveitamento dos resíduos e a adoção de tecnologias e processos mais eficientes, obtêm benefícios através da atração de clientes, trabalhadores e investidores, através da melhoria de imagem, reputação pública da empresa, e pela redução do custo capital motivado pela redução dos riscos provocados pela empresa.

O ponto de partida do presente projeto de investigação firmou-se na ideia de que nas empresas começa-se assistir uma passagem de valores antropocêntricos para valores ecocêntricos. Assim, importa referir que a transformação de valores verificada nas sociedades industrialmente avançadas não é, significativamente, constatada entre as empresas entrevistadas, uma vez que o enraizamento de uma cultura pró-ambiental não se mostra proeminente entre a nossa amostra, sendo que a maioria se encontra inserida no grupo de valores mistos.

Tendo em conta a hipótese qualitativa que colocámos à verificação, isto é, uma melhor informação ambiental aliada a um esclarecimento sobre as questões gerais da ecologia (crenças) estão associados a atitudes e práticas mais amigas do ambiente por parte dos empresários, podemos concluir que de acordo com os dados recolhidos, as práticas ambientais não estão ligadas diretamente à sensibilidade ambiental das empresas, isto porque se pensarmos apenas na dimensão interna, ou seja, planeamento das estratégias económicas, sociais e ambientais, a sensibilidade ambiental poderia realmente estar na essência das práticas ambientais. Mas quando esmiuçamos a questão externa, como imagem junto dos parceiros ou clientes, incluindo parceiros internacionais e consumidores (nacionais e internacionais) cada vez mais defensores dos valores ambientais, a perceção ambiental das empresas toma outro rumo. Ou seja, o que à primeira vista parece um conjunto de práticas amigas do ambiente sob o ponto de vista de uma empresa consciente das suas potencialidades para a proteção do ambiente, em que este seria reconhecido como um lugar determinado ou percebido no tempo onde os elementos naturais estão presentes em relações e em interação, percebidos por meio de opiniões, atitudes, sentimentos e condutas, produzidas no quotidiano, percebemos exatamente o oposto, vimos o ambiente representado como uma potencialidade pelo ponto de vista do mercado. Assim, procuramos perceber as perspetivas das empresas quanto à questão ambiental; como é que estas se colocam e como colocam os outros atores sociais quanto à urgência de atuação; como validam a ocorrência de um programa de ação; que fundamentos usam para salvar ou para reservar-se em relação à adoção de políticas ambientais; como é que 


\section{Responsabilidade Social e Ambiental das Empresas. Uma perspectiva sociológica.}

fomentam os seus pontos de vista em vários setores. A resposta quanto a nós parece passar pela influência da dimensão externa, as estratégias de mercado, a imagem associada a uma empresa amiga do ambiente para novos consumidores, esses sim, cada vez mais conscientes das questões ambientais, obrigam as empresas a ter novas estratégias de forma a obter novos clientes. Ou seja, se o cliente exige produtos amigos do ambiente, se exige processos de produção amigos do ambiente, porquê não? Na nossa sincera opinião, a representação ambiental dos entrevistados não está de todo ligada a uma consciência ambiental mas sim a um mercado mais exigente a nível das questões ambientais e a pressões legais. O ambiente para estas empresas representa mais uma oportunidade de mercado, aliada a um conjunto de vantagens em que todos ficam a ganhar.

No âmbito deste trabalho, é indispensável mencionar o conceito de ecocentrismo. Assim, e no que toca aos valores relativos à biosfera, podemos afirmar que as empresas entrevistadas consideram, na sua maioria, o ambiente como um aspeto importante. Contudo, consideram os lucros e a gestão entre preço e qualidade como aspetos muito importantes das suas empresas. Assim, estes dados mostram que os valores de interesse próprio e altruísmo humanista, aliados ao antropocentrismo, se sobrepõem aos valores altruístas relativos à biosfera, ligados ao conceito de ecocentrismo.

Deste modo, podemos concluir que os entrevistados mostram fracos níveis de mobilização coletiva pró-ambiental. Apesar do número de casos ser exíguo podemos confirmar que as empresas que revelam ter práticas voluntárias para proteção ambiental e incentivo aos trabalhadores, inserem-se na sua maioria no grupo de valores mistos.

A importância dada ao ambiente mostra-se igualmente relevante, visto que os entrevistados que declaram não ter incluído práticas voluntárias são os que consideram o ambiente como um aspeto menos importante, em que o ambiente é um aspeto pertencente a uma melhoria contínua da empresa. Por outro lado, e de acordo com os entrevistados que declaram fazer ou já ter feito práticas voluntárias de cariz ambiental, parecem considerar o ambiente como um aspeto mais relevante. Posto isto, os valores ligados à qualidade de vida e proteção do ambiente mostram alguma influência neste tipo de práticas.

No que concerne à 'cultura' ambiental, poder-se-á dizer que o impacto externo, meios pelos quais as empresas tomam conhecimento, na sua maioria, acerca das questões ambientais, parecem influenciar a escolha das empresas. Assim, independentemente da representação social associada ao ambiente, ou seja, o ambiente como um novo mercado ou como algo a proteger, influenciam as atitudes ambientais, pois todas as empresas entrevistadas apresentam uma atitude positiva em relação ao ambiente. Deste modo, e tendo em conta a quantidade de informação que divulgam perante os trabalhadores para a inclusão de boas práticas ambientais no seu quotidiano, quer seja na empresa ou fora da empresa e 
Maria Paula Vilhena Mascarenhas

Cristiana dos A. Fernandes Costa

independentemente dos objetivos subjacentes às atitudes, às práticas e aos valores, estão a criar-se hábitos que vão ajudar muito a proteger o meio ambiente.

Embora se verifiquem no geral fracos níveis de sensibilidade ambiental entre a nossa amostra, será de extrema importância realçar que os valores pósmaterialistas e valores altruístas relativos à biosfera exercem relativa influência sobre o entendimento ambiental das empresas, uma vez que estão aqui associadas a algumas práticas, individuais e coletivas, consideradas pró-ambientais.

\section{Considerações finais}

A adoção de práticas ou de uma política de gestão que incorpore as questões ambientais depende sem dúvida de fatores que estão ligados a diferenças ao nível da cultura organizacional, sendo que a "predisposição para a mudança" é o fator fundamental para a implementação duma cultura empresarial amiga do ambiente, pois a cultura das empresas é, em última análise, um reflexo dos valores dos seus integrantes.

Contudo, para que a cultura seja incorporada nas empresas tem que começar por existir uma Consciencialização, tem de haver uma apropriação por parte dos diferentes atores da empresa de conceitos como o valor ambiental que potenciem uma tomada de consciência relativamente ao Ambiente e à sua implicação nas diferentes dimensões, nomeadamente na dimensão interna da empresa e na sua interação com o Meio Ambiente, Mercado e a Comunidade.

Havendo uma consciencialização por parte dos atores da empresa a consolidação da mudança terá condições para ocorrer, essa predisposição para a mudança verifica-se estar muitas vezes associada à dimensão da empresa, ou seja, por fatores que têm a ver essencialmente com a disponibilidade de recursos para consolidar as ações, numa lógica de custo/benefício, e da manutenção da competitividade e sustentabilidade futura da empresa.

Este fator também aparece associado a um processo de maturidade e estabilização das empresas, verificando-se que a disponibilidade da empresa e dos seus colaboradores, nomeadamente em termos de tempo, pois no início de atividade é baixa, uma vez que todos os recursos estão orientados e canalizados para a sobrevivência, aumentando a predisposição à medida que a empresa vai amadurecendo e se vai impondo no mercado.

Em empresas não certificadas, havendo predisposição e disponibilidade para assegurar tempos e outros recursos para a consolidação desta cultura, o processo normalmente inicia-se por pequenos passos, podendo dar-se o exemplo da implementação gradativa de pequenas práticas ambientais.

Sendo um processo voluntário, associado cada vez mais a uma lógica de melhoria contínua, torna-se cada vez mais um fator de competitividade das empresas, não só perante os clientes, mas inclusive também ao nível dos benefícios decorrentes duma gestão mais eficaz dos recursos necessários.

Latitude, vol. 7, n², pp.141-167, 2011. 


\section{Responsabilidade Social e Ambiental das Empresas. Uma perspectiva sociológica.}

Esta lógica de melhoria contínua, quando assimilada pelas empresas, acaba por as envolver num processo gradual de mudanças internas, criando uma cultura interna amiga do ambiente e a manutenção da sustentabilidade das suas ações.

Contudo, existe uma diferença entre uma excelência nas organizações e uma verdadeira cultura em prol do ambiente e neste caso o processo acaba por passar para o exterior da própria empresa, não se restringindo a ações pontuais de beneficência ou mecenato, mas uma participação efetiva da empresa na vida da comunidade e na sua relação com outras partes interessadas, que potencia a adoção por parte da empresa de uma postura de cidadania ativa, socialmente responsável.

Este projeto teve como objetivo o diagnóstico da sensibilidade ambiental das empresas com franca incidência nas práticas ambientais, consistindo numa narrativa de práticas concretas, procurando também ajudar a comprovar que a integração duma cultura ambiental é um processo transversal e possível de incorporação por qualquer tipo de organização, seja qual for a sua dimensão ou setor de atividade.

Antigamente, os gestores das empresas pensavam, essencialmente, no valor económico, no lucro. Atualmente, a mentalidade dos nossos gestores está a mudar e começam a dar relevância à proteção ambiental.

A adoção de práticas amigas do ambiente por parte das empresas traz, claro, benefícios, como por exemplo a redução de custos, a racionalização de recursos, a motivação do pessoal, parceiros empresariais mais fiáveis, reforço da competitividade, menor rotação do pessoal e uma melhor comunicação entre colaboradores e acionistas. Embora estejamos todos cientes das melhorias que a adoção destas práticas traz para as empresas, estarão estas preparadas para as abraçar?

Neste aspeto a grande conclusão a que chegamos é que em todas as entrevistas existem práticas amigas do ambiente, revelando-nos uma relação cordial entre a performance económica e a performance ambiental e social.

O ambiente pode e é considerado uma mais-valia nos processos produtivos e organizacionais das empresas entrevistadas. A atitude de disponibilidade para mudar não é limitada mas está sem dúvida condicionada a vários fatores. Se alguma coisa ficou clara foi a generalização da preocupação ambiental por parte dos responsáveis das empresas pela implementação/cumprimento das NP ISO 14001. O panorama está a mudar, sem dúvida, em vários aspetos. No entanto questionamo-nos quais serão as condições que permitirão acelerar as mudanças positivas? Que modos poderão encurtar a distância entre o ideal e o real? Estará a questão ambiental a tornar-se num setor de atividade económica lucrativa? Estará o ambiente a tornar-se num rótulo competitivo?

Estas são apenas algumas interrogações que ficam em aberto e que servirão de reflexão a todos aqueles que terão oportunidade de ler este artigo. Somente 
Maria Paula Vilhena Mascarenhas

Cristiana dos A. Fernandes Costa

quando o debate se tornar mais amplo, mais sincero e sem restrições de um discurso "politicamente correto" é que o ambiente poderá contar com todas as empresas.

\section{Referencias}

ALMEIDA, João Ferreira (org.). Os Portugueses e o Ambiente: I Inquérito Nacional às Representações e Práticas dos Portugueses sobre o Ambiente. Oeiras: Celta Editora, 2000

BERGER, Peter e LUCKMANN, Thomas. A construção social da realidade. Rio de Janeiro: Editora Vozes, 1999.

BERGER, Peter e LUCKMANN, Thomas (1988). A Construção Social da Realidade. Tratado de

Sociologia do Conhecimento. Petrópolis: Editora Vozes [1988], 2003.

CNUAD - Conferência das Nações Unidas sobre o Ambiente e Desenvolvimento, Rio de Janeiro, 1992.

COMISSÃO EUROPEIA: $6^{\circ}$ Programa de Acção Comunitário em matéria de Ambiente 2001-2010. Serviço das Publicações Oficiais da Comunidade Europeia, 2001.

COMISSÃO DAS COMUNIDADES EUROPEIAS: LIVRO VERDE: Promover um quadro europeu para a responsabilidade social das empresas. Bruxelas, 2001.

COSTA, Cristiana. Verdes são os campos. A questão ambiental nas empresas. 2011. Dissertação (Mestrado em Sociologia das Organizações), Universidade do Minho, Braga.

GIDDENS, Anthony. A Constituição da Sociedade. Rio de Janeiro: Martins Fontes, 2003.

GUERRA, Isabel. Pesquisa Qualitativa e Análise de conteúdo-sentidos e formas de uso. Estoril: Príncipia 2006.

KOTLER, Philip e ROBERTO, Eduardo. Marketing social: Estratégias para alterar o comportamento público. São Paulo: campus, 1992. 


\section{Responsabilidade Social e Ambiental das Empresas. Uma perspectiva sociológica.}

KOTLER, Philip. Administração de marketing. 10.ed. São Paulo: Prentice Hall, 2000.

KOTLER, Philip. Marketing para organizações que não visam lucro. São Paulo: Atlas, 1978.

LEVEK, Andrea et. Al.: A responsabilidade social e sua interface com o marketing social, Revista da FAE, no 2 pp. 15-25, 2001

MELO NETO, Francisco Paulo de; FROES, César. Gestão da responsabilidade social corporativa: o caso brasileiro. Rio de Janeiro: Qualitymark, 2001.

MELO NETO, Francisco Paulo e FROES, César. Responsabilidade social \& cidadania empresarial: administração do terceiro setor. Rio de Janeiro: Qualitymark, 1999.

MORGAN, Gareth. Imagens da Organização. S. Paulo: Atlas, 2006.

NETO, Francisco Paulo de Melo e FROES, César. Responsabilidade social $\mathcal{E}$ cidadania empresarial: administração do terceiro setor. Rio de Janeiro: Qualitymark, 1999

NP EN ISO 14001: 2004 (ISO 14001: 1996). Sistemas de Gestão Ambiental. Requisitos e linhas de orientação para a sua utilização, 2004.

NP EN ISO 19011: 2003 (ISO 19011:2002), Linhas de orientação para auditorias a sistemas de gestão da qualidade e/ou ambiente, ISSO, 2003.

NEVES, José Pinheiro e Silva, Esser de Jesus (2010). Ética e responsabilidade social nas organizações: uma abordagem sociológica. Braga: Universidade do Minho, em pdf, cedida pelos autores em 28 de Setembro de 2010.

PARENTE, Cristina. As empresas como espaço de formação, artigo resumido de um capítulo constituinte da dissertação Avaliação de Impacto da Formação sobre as Trajectórias Profissionais e a Competitividade Empresarial: um Ensaio em Empresas do Sector Têxtil do Vale do Ave. 1995. Instituto Superior de Ciências do Trabalho e da Empresa. In http://ler.letras.up.pt/uploads/ficheiros/1394.pdf, acesso em 02 de abril de 2010.

REIGOTA, M. Meio ambiente e representação social. São Paulo: Cortez, 1995.

SROUR, Robert Henry. Poder, Cultura e Ética nas Organizações. São Paulo: Campus, 1998.

SCHWARTZ, M e CARROL, A. Integrating and Unifying Competing and Complementary

Frameworks: The Search for a Common Core in the Business and Society Field. Business \&

Society, v. 20, n. 10, pp. 1-39, Sep. 2007.

THOMPSON, Marjorie e PRINGLE, Hamish. Marketing social: marketing para causas sociais e a construção das marcas. São Paulo: Makron Books, 2000.

VALLE, Cyro: Como se Preparar para as Normas ISO 14000 - Qualidade Ambiental. São Paulo: Pioneira, 1995. 
Maria Paula Vilhena Mascarenhas

Cristiana dos A. Fernandes Costa

WERTHER, J. W. e Chandler, D.. Strategic corporate social responsibility. NewYork: Sage Publications, 2006.

WINTER, Georg: Gestão e Ambiente - Modelo Prático de Integração Empresarial. Lisboa: Texto Editora, 1992.

Latitude, vol. 7, n², pp.141-167, 2011. 